\title{
USE OF ALTERNATIVE WAYS OF GIVING EVIDENCE BY VULNERABLE WITNESSES: CURRENT PROPOSALS, ISSUES AND CHALLENGES
}

\author{
Yvette Tinsley* and Elisabeth McDonald**
}

\begin{abstract}
Fifteen years after the New Zealand Law Commission rejected pre-trial recording of crossexamination, that proposal is back on the reform agenda. Drawing from research examining comparative pre-trial and trial practices in cases of sexual offending, this article discusses the backdrop to the debate surrounding pre-recording, including the provisions of the Evidence Act 2006 and the approach of the courts to alternative ways of giving evidence. The benefits and drawbacks of pre-trial recording of evidence for adult witnesses are canvassed - including practical, evidential and psychological issues - leading to the conclusion that rather than a presumption in favour of any particular alternative way of giving evidence, close consideration of the individual circumstances of each case is required.
\end{abstract}

\section{INTRODUCTION}

In 1996 the New Zealand Law Commission published a discussion paper as part of its 10-year review of the law of evidence which set out options for reform aimed at assisting the gathering of the best evidence from children and some adult witnesses. ${ }^{1}$ Along with extending the use of video recording, video link and CCTV to all witnesses, one of the options supported by the Law Commission in 1996 was pre-trial recording of the cross-examination and re-examination of child complainants, as well as witnesses who are shown to have "an inability to retain and recall

* Yvette Tinsley is Reader in the Faculty of Law, Victoria University of Wellington.

** Elisabeth McDonald is Associate Professor in the Faculty of Law, Victoria University of Wellington. We thank our research assistant, Rachel Souness, for her work on the project this article draws upon.

1 Law Commission The Evidence of Children and Other Vulnerable Witnesses (NZLC PP26, 1996). 
information over time." ${ }^{2}$ The proposals were said to be consistent with the purposes of New Zealand's proposed Evidence Code in the following ways: ${ }^{3}$

Pre-trial cross-examination will decrease trauma and stress for most child witnesses. It allows a child's participation in the proceedings to end at a much earlier stage so that counselling and support can focus on recovery, rather than trial preparation. Pre-trial cross-examination means that evidence will be fresher and therefore likely to be more accurate and reliable.

The Law Commission's discussion paper, The Evidence of Children and Other Vulnerable Witnesses, was reviewed by overseas commentators, one of whom concluded: ${ }^{4}$

The New Zealand Law Commission is to be congratulated for producing an imaginative, thoughtful and well-researched Discussion Paper. Its refusal to become bogged down in conventional legal assumptions and platitudes is refreshing, and also reassuring in proving that law reform bodies are capable of creative thinking and genuine innovation.

Despite this reaction, after consulting the legal profession, and other interested individuals and groups, the Law Commission did not recommend the introduction of pre-trial cross-examination in its final report "[u]ntil more is known about the experiences of other jurisdictions with pre-trial cross-examination". 5 The reason for this decision was because although the proposals "received strong support from a wide range of community groups and some practitioners", they were met with "almost unanimous opposition from the defence bar." ${ }^{6}$

2 Ibid, at [146].

3 Ibid, at [145]. In this work the Law Commission cited the Western Australian legislation: ss 106I-106MB of the Evidence Act 1906 (WA). A more recent study on the effects of such procedures indicates that when children are only cross-examined once and not at trial this positively affects their well-being and experience: see Christine Eastwood and Wendy Patton The Experience of Child Complainants of Sexual Abuse in the Criminal Justice System (Criminology Research Council, Australian Institute of Criminology, 2002) at 58. See also Kirsten Hanna and others Child Witnesses in the New Zealand Criminal Courts: A Review of Practice and Policy (AUT Institute of Public Policy, Auckland, 2010) at 127-129, 147-152 and 179.

4 Jenny McEwan "The Evidence of Children and Other Vulnerable Witnesses: A Discussion Paper" (1998) 2 E\&P 32.

5 Law Commission Evidence: Reform of the Law (NZLC R55 Vol 1, 1999) at [460]. Since the publication of the report and draft Code, there have been a number of other jurisdictions that have adopted or are conducting pilots on the use of pre-trial cross-examination - for example s 271I of the Criminal Procedure (Scotland) Act 1995. See further generally Laura Hoyano and Caroline Keenan Child Abuse Law and Policy Across Boundaries (Oxford University Press, Oxford, 2007). Given that there is now information from other jurisdictions available, it may be appropriate for New Zealand to consider the use of pre-trial crossexamination more regularly. Although it may well be possible for the practice to develop as part of the exercise of a court's inherent jurisdiction (Evidence Act 2006, s 11), because of the concerns of the profession and the argument that the Evidence Act 2006 does not provide statutory authority, it may be a matter best left for legislative regulation.

6 Law Commission Evidence: Reform of the Law, above n 5, at [459]. 
Notwithstanding that the Law Commission did not recommend the introduction of pre-trial cross-examination, the provisions dealing with the use of alternative ways of giving evidence in the Evidence Act 2006 (which in large part enacted the Law Commission's draft Code) ${ }^{7}$ did not prohibit the use of pre-trial cross-examination, although the wording of s 105 may be read as not providing for pre-trial cross-examination. ${ }^{8}$ Since the Act came into force on 1 August 2007, there have been at least two cases in which pre-trial cross-examination has been permitted at the High Court level (regarding adult witnesses). ${ }^{9}$ Further, as a consequence of a recent successful District Court application, ${ }^{10}$ there are likely to be many child complainants in sexual cases whose evidence will be pre-recorded. To this end, the Ministry of Justice have released an operational circular outlining the process to be followed in conducting pre-recorded evidence hearings. ${ }^{11}$

Fifteen years after the Law Commission's consideration of the value of pre-trial recording of cross-examination, it is timely to re-examine the arguments both in support and against such a practice. It is timely because, despite its rejection by the Law Commission in 1999, pre-trial crossexamination is being condoned by the courts in 2011. Also, calls for reform in relation to the participation of child witnesses led the Ministry of Justice to release an Issues Paper in December 2010, in which it asked whether "pre-recording children's entire evidence should be the 'usual' way a child should give evidence?"12 Further, the Law Commission has been asked by the Government to consider reform to pre-trial and trial processes, with particular reference to complainants in cases of sexual offending. Such work necessarily involves discussion of the use of alternative ways of giving evidence by adult complainants. The Law Commission's work is being done in collaboration with the authors who have received Law Foundation funding to examine comparative pre-trial and trial practices in cases of sexual offending in overseas jurisdictions. ${ }^{13}$

7 Section 103(1) of the Evidence Code provided that the judge could direct that a witness could be directed to "be cross-examined ... in an alternative way": Law Commission Evidence: Evidence Code and Commentary (NZLC R55 Vol 2, 1999) at [234].

8 See further Richard Mahoney and others The Evidence Act 2006: Act and Analysis (2nd ed, Brookers, Wellington, 2010) at [EV103.02].

$9 \quad R v$ Kereopa [2008] DCR 29 (HC); $R v$ Willeman [2008] NZAR 644 (HC).

$10 R v$ Sadlier DC Auckland CRI-2010-044-4165, 7 December 2010.

11 Ministry of Justice "Pre-recording of Evidence (s103 to 107 Evidence Act 2006)" (CRM/11/05 and HCG/11/05, Ministry of Justice, 19 April 2011) [Ministry of Justice CRM/11/05 and HCG/11/05]. At present, such hearings are likely to be limited because courts do not have the equipment in-house to fully conduct hearings where audio and video are captured to DVD.

12 See Question 4: Alternative Pre-trial and Trial Processes for Child Witnesses in New Zealand's Criminal Justice System: Issues Paper (Ministry of Justice, Wellington, 2010) at [87]. This document is on file with the authors. [Ministry of Justice Issues Paper].

13 Along with Professor Jeremy Finn from the University of Canterbury: "Is the criminal justice system failing victims?" (2009) Scoop Independent News <www.scoop.co.nz>. 
In this article, we start by outlining the scope of our research and the events that gave rise to a renewed public concern regarding the treatment of rape complainants within the criminal justice process. We then discuss the current law concerning the use of alternative ways of giving evidence, which includes consideration of the provisions in the Evidence Act 2006 and the Courts (Remote Participation) Act 2010 and the relevant cases decided under those provisions. In the next part of the article we outline the recent calls for reform and respond to the specific proposals and recommendations. We do so by drawing on the current psychological research and by identifying the practical and evidential challenges of an increased use of alternative ways of giving evidence, including the recording and use of pre-trial cross-examination. We conclude that, in the absence of scientific evidence that alternative ways of giving evidence undermine a fair trial (by either having an effect on eventual verdicts or adversely affecting the ability of fact-finders to make credibility assessments), the potential for pre-recording evidence of vulnerable witnesses should be explored further. However in our view, alternative ways of giving evidence should continue to be assessed for each witness in the context of each individual case.

\section{COMPARATIVE TRIAL PROCESS RESEARCH}

For more than 35 years, those working in the New Zealand criminal justice system have been concerned about the experiences of women victims of sexual violence who testify in court as complainants. ${ }^{14}$ Sixteen years ago, Thomas J had this to say: ${ }^{15}$

The extreme distress of a complainant giving evidence in a rape case and reliving the trauma of the ordeal in the witness box, can be seen in the Courtroom at any time. It is not an uncommon occurrence, and it is done in the name of justice. But there can be no justice in a practice which brutalises the victim of a crime in a way which is repugnant to all civilized persons. It is inexplicable that the practice can be tolerated with such equanimity.

Thomas $\mathbf{J}$ was writing ten years after the publication of a report that resulted in a number of significant changes to the trial process. ${ }^{16}$ Many of these changes impacted significantly, and positively, on the experience of complainants in sexual cases. Others have been less successful in their implementation. Although academics, lawyers, judges and community workers continued to

14 See discussion of the reform of the Evidence Act 1908 in 1977 when the "rape shield" provision, s 23A, was enacted in recognition of local research at the time. See for example: Ann Lloyd Rape: an examination of the crime in New Zealand: its social and emotional consequences (Wilson and Horton, Auckland, 1976). For academic commentary preceding the 1985 reforms see Margaret Wilson "Sexual Violence - A Feminist Perspective" in Papers Presented at Seminar: Sexual Violence: a Case for Law Reform (Legal Research Foundation, Auckland, 1982).

15 EW Thomas "Was Eve Merely Framed; or was She Forsaken?" [1994] NZLJ 368 at 372.

16 Warren Young Rape Study Volume 1: A Discussion of Law and Practice (Department of Justice, Wellington, 1983). For a discussion of the consequential reforms see Gerry Orchard "Sexual Violation: The Rape Law Reform Legislation" (1986) 12 NZULR 97. 
express concern about the low reporting and conviction rates in sexual cases, it was not until a high profile case in 2006 that the public became engaged and two successive governments were compelled to act.

In the mid-1980s a number of young women claimed they were gang-raped by three police officers in the Bay of Plenty, New Zealand. Although complaints were made at the time, no action was taken until a journalist highlighted the issue in 2004. In March 2006, the three men were acquitted of raping one of the women. ${ }^{17}$ Public concern about the case initially centred on the fact that the jury were not told that two of the accused had been convicted of raping another of the young women. ${ }^{18}$ The Government responded in a number of ways to this public disquiet. Significantly, the Rt Hon Helen Clark, the Prime Minister at the time stated: ${ }^{19}$

[I]n my opinion, no reasonable person would think that a troubled teenage girl engaging in group sex with police officers in a regional town would believe that there [was genuine] consent.

In July 2007, following a third trial in which the police officers were acquitted, the Government set up a Taskforce for Action on Sexual Violence "to lead and co-ordinate efforts to address sexual violence and advise Government on future actions to prevent and respond to this crime. ${ }^{20}$ In the same month, the Ministry of Women's Affairs, in partnership with the Ministry of Justice and the New Zealand Police, commenced a two-year research project into sexual violence against adults in New Zealand. ${ }^{21}$

17 Louise Nicholas, the woman in question, chose to be named. See Louise Nicholas and Philip Kitchin Louise Nicholas: My Story (Random House, Auckland, 2007).

18 This woman was subsequently required to testify in a case against two ex-police officers who were charged with perverting the course of justice. She sought to have the same protections she was entitled to as a complainant in a sexual assault trial (such as protection of her name and identity and restrictions on questions relating to her sexual experience) applied when she gave evidence a second time. See $R v$ Mangnus HC Auckland CRI-2006-004-7577, 16 August 2007 at [38]:

Ms Z has specifically sought such protection. She has sworn a supporting affidavit in which she says she found giving evidence at the 2005 trial was a very stressful ordeal. She had to relive the whole event of being raped by a number of different men. At one stage during her evidence the trial judge granted a brief adjournment because she felt she was going to faint. She also states: I am willing to give evidence in the current proceeding. However, I am only prepared to do so if I am afforded the same protections that I was given when I gave evidence at the first trial.

19 Paula Oliver "Rickards: It's a matter of pride" (2007) New Zealand Herald <www.nzherald.co.nz〉.

20 Ministry of Justice "The Taskforce for Action on Sexual Violence" (2009) <www.justice.govt.nz>

21 Ministry of Women's Affairs "Sexual Violence Research Project: Research Reports" (2009) <www.mwa.govt.nz>. 
The Law Commission was specifically asked by the Government to consider the issue of the disclosure of an accused's previous convictions at trial. In the foreword to their May 2008 report, the Commission concluded: ${ }^{22}$

[T]here could be value in investigating whether the adversarial system should be modified or replaced with some alternative model, either for sex offences or for some wider class of offences.

The Law Commission was subsequently asked by the Government to undertake this investigation and is doing so in conjunction with the authors. ${ }^{23}$

One of the aspects of this research, which has not only focussed on reforms to the current pretrial and trial process, ${ }^{24}$ is the possibility of gathering evidence from witnesses in a different way and at a different stage. The current adversarial system, or that which operates primarily in common law jurisdictions, places much faith in the oral tradition - based on a belief that the best way of testing the evidence of witnesses and therefore having confidence in a verdict is by having the witness present in the courtroom and being cross-examined by the opposing party. ${ }^{25}$ Although for some time there have been accepted departures from that usual or "ordinary" way of giving evidence, ${ }^{26}$ for example the use of a pre-recorded evidential interview as a child complainant's evidence in chief, ${ }^{27}$ indications that such departures should be more common are met with some resistance. $^{28}$

In civil law jurisdictions, which are sometimes described as being closer to an inquisitorial model, less emphasis tends to be placed on oral evidence at trial, although in some places (for

22 Law Commission Disclosure to Court of Defendants' Previous Convictions, Similar Offending, and Bad Character (NZLC R103, 2008) at v.

23 Above n 13. See also Law Commission "Alternative models for prosecuting and trying criminal cases" (2009) <www.lawcom.govt.nz>.

24 It is clear that reform of the existing criminal justice system will not of itself affect the incidence of sexual offending nor victim/survivor satisfaction without examination of options for those who choose not to participate in the criminal justice process. As sexual offences remain one of the least reported crimes, other ways of responding to those involved in the offending, whether as victim, perpetrator or members of either person's community or whanau must be considered and evaluated also. A discussion on a range of options for the resolution of incidents of sexual offending is included in the authors' research report: Elisabeth McDonald and Yvette Tinsley (eds) From "Real Rape" to Real Justice: Prosecuting Rape in New Zealand (forthcoming, Victoria University Press, 2011).

25 Paul Roberts and Adrian Zuckerman Criminal Evidence (2nd ed, Oxford University Press, Oxford, 2010) at 55.

26 Evidence Act 2006, s 83

$27 R v M$ (CA 590/2009) [2009] NZCA 455 at [39].

28 See $R v$ SJP HC Auckland CRI-2009-004-22634, 13 July 2010 at [28]. See also Ministry of Justice Issues Paper, above n 12, at [55]. 
example the Nordic countries), what is heard at trial will usually form the factual basis of the decision. ${ }^{29}$ Despite regional variations with regard to the importance of the trial "dossier", ${ }^{30}$ in most jurisdictions pre-trial recording of some witness's evidence can replace their attendance at trial. Mostly this process is only available for child complainants in cases of sexual offending. ${ }^{31}$ However in some jurisdictions, for example Austria, ${ }^{32}$ the so-called "contradictory interrogation" is also available for adult complainants in sexual cases. ${ }^{33}$ This is where the witness is asked questions only by the judge (or sometimes an expert) in a separate room, but as a result of consultation with the prosecution and defence.

To propose a process whereby the judge is primarily responsible for directing the gathering of the evidence, or the questioning of the witnesses either before trial or at trial, would be a marked departure from the adversarial party-led model. It would also require not only significantly more judges (to give them time to get to know each case in sufficient detail), it would require judges to have a different skill set. ${ }^{34}$ Although there are some advantages in increasing the role of the judiciary in this way (for example it may allow them to more effectively control witness questioning and the admissibility of evidence in a timely way), the advantages may still be gained without such a significant change to the trial process.

One of the possible changes that would address some current concerns is an increased use of pre-recording of a witness's entire evidence. Such a practice would allow earlier recovery by a victim/survivor, especially in cases of sexual offending; reduce the trauma involved in participating in the criminal justice process; and capture and preserve the witness's evidence at a time when their memory is fresh. ${ }^{35}$ The recording could be used not only at the trial as the witness's evidence, it could also be used at any re-trial, although perhaps supplemented in some cases by further

29 Ulf Stridbeck and Par Anders Granhag "Legal procedures in the Nordic countries and in the USA: A comparative overview" in Par Anders Granhag (ed) Forensic Psychology in Context: Nordic and International Approaches (Willan Publishing, Portland (Oregon), 2010) 14 at 24.

30 The dossier is primarily the evidence to be considered by the fact-finders in the Netherlands, whereas in Germany, for example, greater emphasis is placed on the evidence of the witnesses at trial - although not all witnesses are required to give evidence.

31 See Emily Henderson "Innovative Practices in Other Jurisdictions" in Hanna and others, above n 3, 117 at 117.

32 Ministry of Justice Issues Paper, above n 12, Appendix C.

33 Ibid, Appendix C at [10].

34 Ibid, at [98]. However our research (undertaken by interviewing judges in Austria, Germany, the Netherlands and Denmark) indicated that judges in those jurisdictions do not receive special training to deal with victims of sexual offending.

35 Ibid, at [72]. 
examination in chief and cross-examination. In 1996 the Law Commission expressed the view that: ${ }^{36}$

All these points indicate an increased likelihood that fuller and more accurate evidence will be available to the court. It may be that the quality of the evidence generally would be improved if all witnesses'

evidence were recorded on videotape close to the time of the incident.

In the context of the current research project however, consideration is being given primarily to reforms that may assist complainants in cases of sexual offending to give their best evidence, while still allowing appropriate testing of that evidence by the defendant. In this way fairness to both witnesses and the defendant is being accommodated, as required by the principles of the Evidence Act.

In the next part of the article, we discuss how the Evidence Act is currently being applied with reference to the use of alternative ways of giving evidence, before discussing the proposed reforms and the extent to which those proposals will effect principled improvements to the current factfinding process.

\section{THE CURRENT LAW GOVERNING THE USE OF ALTERNATIVE WAYS OF GIVING EVIDENCE}

\section{A The Scope of the Evidence Act 2006 and the Courts (Remote Participation) Act 2010}

Sections 102A-107 of the Evidence Act, together with the Evidence Regulations 2007, governs the use of alternative ways of giving evidence in proceedings to which the Evidence Act applies. ${ }^{37}$ Section 123 of the Evidence Act deals with judicial directions that should accompany "certain ways of offering evidence".

With regard to the evidence of complainants in sexual cases being presented in an alternative way, it is the Evidence Act that is the applicable legislation, not the Courts (Remote Participation) Act 2010. ${ }^{38}$ This means that the inquiry under s 5 of the Courts (Remote Participation) Act into "the ability to assess the credibility of witnesses" is not an explicit consideration for a judge giving directions under s 103 of the Evidence Act. Such an inquiry could be part of the consideration of the impact that the alternative way of giving evidence may have on the fairness of the proceeding ( $\mathrm{s}$ 103(4)(a)(i)). However judges have been unwilling to refuse an application on the basis of the

36 Law Commission Children and Other Vulnerable Witnesses, above n 1, at [145].

37 See Evidence Act 2006, s 5 and the definition of "proceedings" and "Court" in s 4.

38 This is clarified in the Evidence Act, s 102A. This is an improvement on the relevant clause in the Courts (Remote Participation) Bill 2009 (107-1), which did not reflect an understanding of the significance of s 5 of the Evidence Act. See further Mahoney and others, above n 8, at [EV102A.01]. 
alleged inability by the fact-finder to assess credibility. ${ }^{39}$ Even prior to the Evidence Act, Hugh Williams J expressed the view that: ${ }^{40}$

$[\mathrm{T}]$ here is no difference in principle between having a witness present in person in the witness box giving evidence and the same person being effectively present in the courtroom with his or her image portrayed electronically. Technology nowadays is such that, even in cases where credibility is the issue, people commonly make judgments on such issues on nothing more than electronic images.

Indeed, for many people, television and electronic media are their principal sources of information about the World. They make judgments, big and small, political, legal and moral, largely or solely on what they see depicted on a screen. So it would be odd if, in the 21 st century, courts were to refuse to use such technology and insist on compliance with an aphorism which long pre-dates the electronic age.

Later in the article we discuss the extent to which his Honour's observation (and that of the Court of Appeal in $R v$ Simi) that "evidence by video link has not previously been seen as adversely affecting an ability to assess credibility", ${ }^{41}$ is an accurate reflection of the current research into the decision-making process of judges and juries. Such research tends to suggest that the inquiry included in s 5 of the Courts (Remote Participation) Act is not the most helpful way of giving guidance to the exercise of discretion. ${ }^{42}$

\section{$B$ The Operation of the Evidence Act 2006 Provisions}

The primary empowering provision regarding the use of alternative ways for witnesses to give evidence in criminal proceedings is s 103 of the Evidence Act. Section 105 defines what kind of directions the judge may give - in essence a definition of what is an acceptable "alternative way". Sections 104 (the requirement of a hearing in chambers) and 106 (the use and admissibility of a video record) are procedural. Section 107 is similar in content to s 103, in terms of the grounds for giving a direction, but it is important to note that it also contains a requirement in s 107(1) that "in a criminal proceeding in which there is a child complainant, the prosecution must apply to the court

39 See the discussion of the use of video link in Deutsche Finance New Zealand Limited v Commissioner of Inland Revenue (2007) 18 PRNZ 710 (HC) at [14]; Omni Marketing Group, Asia Pte Limited v Transactor Technologies Limited HC Auckland CIV-2007-404-430, 29 May 2008 at [15]; Yang $v$ Chen HC Auckland CIV-2007-404-1751, 13 May 2010 at [52]; $R$ v Ming HC Auckland CRI-2009-092-10550, 26 August 2010 at [36].

$40 \quad R v$ Wong HC Auckland CRI-2005-004-15296, 17 May 2006 at [55]-[56].

$41 R v$ Simi [2008] NZCA 515 at [27]. See also $R v$ Raj [2007] NZCA 10 at [44]; $R v$ Williams HC Auckland CRI 2009-092-10225, 16 December 2009 at [30]; $R v$ Check [2009] NZCA 548 at [78]. In $R v$ Munro [2008] NZCA 87, [2008] 2 NZLR 87 at [76], an appeal heard prior to the Evidence Act, the Court of Appeal cited research that expressed doubt as to the ability of jurors to accurately make decisions about the credibility of witnesses even when they give evidence "live" in a courtroom.

42 HK Orcutt and others "Detecting deception in children's testimony: fact finders' abilities to reach the truth in open court and closed-circuit trials" (2001) 25 Law \& Human Behav 339. 
... for directions about the way in which the complainant is to give evidence in chief and be crossexamined." A child complainant is defined in s 4 of the Act as a person under the age of 18 "when the proceeding commences." 43

\section{Section 103 provides:}

(1) In any proceeding, the Judge may, either on the application of a party or on the Judge's own initiative, direct that a witness is to give evidence in chief and be cross-examined in the ordinary way or in an alternative way as provided in section 105 .

(2) An application for directions under subsection (1) must be made to the Judge as early as practicable before the proceeding is to be heard, or at any later time permitted by the court.

(3) A direction under subsection (1) that a witness is to give evidence in an alternative way, may be made on the grounds of-

(a) the age or maturity of the witness:

(b) the physical, intellectual, psychological, or psychiatric impairment of the witness:

(c) the trauma suffered by the witness:

(d) the witness's fear of intimidation:

(e) the linguistic or cultural background or religious beliefs of the witness:

(f) the nature of the proceeding:

(g) the nature of the evidence that the witness is expected to give:

(h) the relationship of the witness to any party to the proceeding:

(i) the absence or likely absence of the witness from New Zealand

(j) any other ground likely to promote the purpose of the Act.

(4) In giving directions under subsection (1), the Judge must have regard to-

(a) the need to ensure-

(i) the fairness of the proceeding; and

(ii) in a criminal proceeding, that there is a fair trial; and

(b) the views of the witness and-

(i) the need to minimise the stress on the witness; and

43 "Proceeding" is defined in s 4 to include an interlocutory or other application connected with the proceeding (which only includes those "conducted by a court"). 
(ii) in a criminal proceeding, the need to promote the recovery of a complainant from the alleged offence; and

(c) any other factor that is relevant to the just determination of the proceeding.

The significant point to note is that s 103 empowers the judge to direct that any witness, including a defendant in a criminal proceeding, may give evidence in an alternative way. This could include both evidence in chief as well as cross-examination and re-examination - either under the Evidence Act, or if necessary this could occur in the exercise of the court's inherent jurisdiction, as occurred in relation to the use of screens, for example, in the case of adult complainants in sexual cases before the Evidence Act came into force. ${ }^{44}$

The grounds for making a direction are set out in s 103(3), and with regard to the situation of complainants in sexual cases paras (c), (f), (g), and in some cases (h), will be of most relevance. The judge must also "have regard to" the views of the witness, the need to minimise stress on the witness and the need to promote recovery ${ }^{45}$ - all matters which will be of significance in the context of sexual offending. Subsection 4(a) also refers to fair trial considerations - a specific reminder of the importance of those matters also contained in s 6 of the Evidence Act.

Since the Evidence Act came into force, adult complainants in sexual cases have been permitted to give evidence from behind a screen, ${ }^{46}$ via video-link from overseas, ${ }^{47}$ via CCTV, ${ }^{48}$ and by prerecorded video record. ${ }^{49}$ The issues remaining are therefore not the absence of availability of alternative ways of giving evidence - they instead relate to victims being advised of the possibility of giving evidence in an alternative way, whether any standard of proof must be satisfied in order for the direction to be made, or if there is any presumption in favour of the ordinary way of giving evidence.

\title{
1 Information and consultation about the use of alternative ways of giving evidence
}

Aspects of the trial process which a complainant will want to know about are the possibility of any alternative ways of giving evidence, as well as the physical layout of the courtroom, including

\author{
44 See Mahoney and others, above n 8, at [EV103.01]. \\ 45 Evidence Act, s 103(4). \\ 46 Mussa v R [2010] NZCA 123. \\ $47 \quad R v$ Simi, above n 41. \\ 48 R Ashby HC Whangarei CRI-2009-027-3088, 13 December 2010. \\ $49 R v$ Willeman, above $\mathrm{n} 9$.
}


(safe) access and waiting rooms. In Victims of Crime - Guidance for Prosecutors (Guidance for Prosecutors) this information is seen as being appropriately delivered by Victim Advisors: ${ }^{50}$

Prosecutors should ensure that victims have been referred to Court Services for Victims. Victim Advisors can assist by explaining the Court process, showing the victim the courtroom and ascertaining and communicating the views of victims. They can also ensure that victims with special needs have an appropriate support person organised in the courtroom if required and ensure that other special arrangements of the trial are made ...

In cases involving sexual offending the prosecutor should ensure that arrangements have been made for the victim to meet with a Victim Advisor or specialist support worker where available, before the hearing or trial, to explain the Court process and show the victim the Courtroom. Any alternative means of giving evidence (eg behind a screen) should be shown to the victim and explained.

In providing that Victim Advisors communicate the views of victims, this guidance, suggests that a third person conveys information from the complainant to the prosecutor - particularly in this context with regard to the use of alternative ways of giving evidence. The difficulty here is that the Victim Advisors, while certainly able to demonstrate how the alternative ways might work, are not in a position to say whether such means will be available to the particular complainant. Although their preference might be conveyed back to the prosecutor, as the prosecutor will be making any application for the use of alternative ways (or the attendance of a particular support person), they will be best placed to make the relevant inquires of the complainant and to advise as to likely outcome. In the words of a Victim Advisor: ${ }^{51}$

Often victims tell us that they have information and knowledge of the crime that the Crown is unaware of, and establishing a relationship between prosecutor and victim allows for a better prosecution, and mostly likely, a better chance of conviction. As it is, prosecutors may not know the best questions to ask, as they have the minimum information ... Victims have expressed frustration and lack of trust in the prosecution process, and feel disempowered by this distance between victim and prosecutor.

In England the Crown Prosecution Service Policy provides that when it is decided that the prosecutor will make an application for special measures (alternative ways of giving evidence), the prosecutor will ask police if the witness wants to meet with the prosecutor. It is the Police Officer or Witness Care Officer who will usually have received the relevant information regarding the application. ${ }^{52}$ The stated purpose of such a meeting is. ${ }^{53}$

50 Victims of Crime - Guidance for Prosecutors (Crown Law Office, 2010) at [11] and [13] [Guidance for Prosecutors].

51 Elaine Mossman and others Responding to Sexual Violence: environmental scan of New Zealand agencies (Ministry of Women's Affairs, 2009) at 121.

52 CPS Policy for Prosecuting Cases of Rape (Crown Prosecution Service (UK), 2009) at [7.9]. 
[T]o build trust and confidence and enable us to reassure the witness that their needs will be taken into account. We will also offer such a meeting if we have decided not to apply for special measures so that we can explain that decision.

This process addresses the concerns outlined above which might arise in the absence of any discussion directly between the prosecutor and the complainant.

Aside from being more involved in the decision to apply for the use of alternative ways of giving evidence, complainants currently may not be aware of these protections, or know how to enforce them. A Ministry of Women's Affairs funded study interviewed victims who had been involved in court processes. Only two of the 11 interviewed said they had been given a choice about the mode of giving evidence, although the authors acknowledge that as there were only a small number of interviews and the sample was not representative, these findings must be interpreted with caution. ${ }^{54}$ Nevertheless, it is of concern that such a small proportion of interviewees felt they had been given a choice about the way in which they gave evidence. While not all complainants will wish to give evidence behind screens, it is important that they are advised of the possibility, not only to facilitate the way they give evidence, but also as a method of ensuring their involvement in their case.

In the same study complainants were asked what they thought could be done to improve court processes for sexual assault complainants. Suggestions included using screens when complainants gave evidence and having support available throughout for complainants. ${ }^{55}$ A complainant is of course entitled to have a support person near her when giving evidence ${ }^{56}$ and a screen may be used upon application. ${ }^{57}$ These suggestions by complainants who had been through the criminal justice system lend support to the conclusion that existing support mechanisms may not be adequately explained or outlined to complainants. Even if they are not utilised, there is still merit in ensuring victims are aware of the potential measures that may assist their experiences in the criminal justice system. Although information about the availability of such assistance can be provided by a Victim

53 Ibid, at [7.10]. The Crown Prosecution Service has also issued a leaflet for victims providing information about meetings with the prosecutor. See "Witnesses: About your Meeting with the CPS Prosecutor" (2011) Crown Prosecution Service <www.cps.gov.uk>.

54 Venezia Kingi and others Responding to sexual violence: Pathways to recovery (Ministry of Women's Affairs, 2009) at 20 and 95. Eight-four per cent of prosecutors interviewed thought that use of screens and closed-circuit television was a good idea if it helped the victim to relax and give clear coherent evidence: Mossman and others, above n 51, at 112.

55 Ibid, at 102 .

56 Evidence Act, s 79.

57 Evidence Act, s 103. 
Advisor, or even by way of a pamphlet, ${ }^{58}$ as noted above there may be in most if not all cases, a need for fuller discussion about the likelihood of such measure being available to the particular complainant. Unless the Victim Advisor has specialised training in this area, ${ }^{59}$ such discussion should be undertaken with the prosecutor, or some other person with the appropriate knowledge and expertise.

In the Ministry of Justice's 2009 Consultation Document, A Focus on Victims of Crime: A Review of Victims' Rights, Preliminary Proposal 5 was that "prosecutors offer to meet with (or otherwise contact) victims of serious crimes if possible at a time prior to the first court hearing."60 Research suggests that meeting with prosecutors prior to trial is likely to ensure victims feel better prepared and more involved in the criminal justice system. ${ }^{61}$ In the Ministry of Women's Affairs funded study, when victims of sexual offending asked what could be done to improve the court process, one of the suggestions was to meet with the Crown Prosecutor at an earlier time. ${ }^{62}$

After reviewing submissions on the Consultation Document, the Minister of Justice announced that one of the reforms in the "victim's package" would improve victim-prosecutor communications. ${ }^{63}$ However, the only relevant recommendation made was that the Police Prosecution Service's Statement of Policy and Practice be amended to provide that police prosecutors (or their delegate, who will usually be the officer in charge of the case) must take reasonable steps to contact victims of sexual offending before the trial. ${ }^{64}$ This was seen as important as it would align the practice with that set out in the Guidance for Prosecutors. However, the timing

58 See Ministry of Justice "For Victims of Sexual Violence: Moving Through the Criminal Justice System" (2010) at <www.justice.govt.nz>. Note however that this does not give information about the role of the prosecutor and, contrary to the Guidance for Prosecutors, above n 50, indicates that the prosecutor "will help you if you have been called as a witness" and make sure victims know what support options are available and how they work (at 14-15). A much more comprehensive and accessible publication written by women in 1993 could helpfully be updated and reprinted: see Wellington Community Law Centre Rape Survivors' Legal Guide (Wellington, 2003).

59 Currently Victim Advisors are not specially trained regarding sexual offending (see Mossman and others, above $\mathrm{n}$ 51, at 29) - but they do provide advice and act as a liaison between victims, officer in charge of the case and prosecutor. See also Kingi and others, above n 54, at 102.

60 A Focus on Victims of Crime: A Review of Victims' Rights - Public Consultation Document (Ministry of Justice, 2009) at 27.

61 Vivian Stern The Stern Review: Independent Review into how Rape Complaints are Handled by Public Authorities in England and Wales (Government Equalities Office and Home Office, 2010) at 81-83 [The Stern Review].

62 Most victims only meet the prosecutor on the day of the trial. Kingi and others, above n 54, at 83 and 102.

63 Simon Power, Minister of Justice "Speech to the Working with Sexual Violence Symposium" (Auckland, 6 May 2011).

64 Cabinet Paper "Enhancing Victims' Rights Review" (17 February 2011) <www.justice.govt.nz> at [39]. 
and content of such a meeting is also of importance. In Appendix 1 to the Cabinet Paper, which sets out the costs and benefits of the proposals, it is stated that the proposed "[m]eetings with victims are likely to be short and to occur on the day of the hearing." 65 Such meetings can therefore not meet the stated needs of complainants in cases of sexual offending, nor will they be timely in terms of ascertaining the views of the complainant as to the use of any alternative ways of giving evidence. The concerns expressed above therefore remain unanswered.

\section{No presumption in favour of the "ordinary way"}

No specific standard of proof for the ordering of use of alternative ways of giving evidence is included in the Evidence Act, and there is no presumption in favour of the "ordinary way" or any express balancing exercise required. ${ }^{66}$ Courts are required to "give regard to" the matters in ss 103(4) and 107(4) but no particular matter is given more weight. Recourse could be made to the s 8 balancing test, although this refers to the admissibility of evidence rather than modes of evidence, ${ }^{67}$ and s 6 only provides a list of purposes to be considered when applying the Act. ${ }^{68}$

In $R v$ Shone the Court of Appeal stated, with regard to ss 103 and 107, that "the general jurisdiction which Parliament has provided" should not be read down by introducing "presumptive positions, so long as proper regard is had to the fairness of the proceeding. "69 In the High Court however, judges have been inclined to either begin from a presumption "in favour of evidence being given in the usual manner with an accused being able to view the witness", ${ }^{70}$ or preferring a

65 Ibid, at 23.

66 There is no particular reference to these matters in the work of the Law Commission except the following from Law Commission Children and Other Vulnerable Witnesses, above n 1, at [130]:

The test would refer to the purpose of rational ascertainment of facts (that is, the promotion of reliable evidence and effective communication) as well as the desirability of minimising unnecessary distress. These goals would be balanced against the need to ensure the fairness of the proceeding, and, in particular, that a defendant in a criminal case has a fair trial.

67 See the discussion in Mahoney and others, above n 8, at [EV12.02]. Compare $R v M(C A$ 590/2009), above n 27, at [31].

68 Omni Marketing Group, Asia Pte Ltd v Transactor Technologies Ltd, above n 39, at [9].

$69 R v$ Shone [2008] NZCA 313 at [28]. See also the pre-Evidence Act decision in $R v$ Raj [2007] NZCA 10 at [34] in which the Court of Appeal observed:

More than fifteen years ago Parliament saw fit to introduce a regime to minimise the potential for young complainants in sexual cases being re-traumatised by the court process. Mechanisms were created for alternative ways or receiving evidence. There is no presumption for or against their use, but they are available and must be evaluated in relevant circumstances.

$70 R v$ Briggs HC Whangarei CRI-2008-027-60, 13 March 2009 at [12]; $R v$ SJP HC Auckland CRI-2009-00422634, 13 July 2010 at [28]. In $R v$ Williams HC Auckland CRI-2009-092-10225, 16 December 2009 Heath $\mathrm{J}$ talked of being "satisfied that the threshold for ordering that evidence be given in an alternative way has been crossed" at [26]. 
balancing exercise "whereby the ground(s) established and other applicable factors from s 103(4) will be considered."71 This can be contrasted with the Court of Appeal's view that in the case of child complainants, "evidence will normally be given by way of video record if there is one, unless there are exceptional circumstances."72

We disagree that the Evidence Act contains a presumption in favour of the "ordinary way", but whether a presumption in favour of the use of alternative ways of giving evidence should be introduced with regard to child witnesses is one of the current options for reform we will now discuss.

\section{RECENT REFORM PROPOSALS CONCERNING THE USE OF ALTERNATIVE WAYS}

The two current reform proposals that will be considered in the next part of the article come from the recommendations in the work of Kirsten Hanna and others published in Child Witnesses in the New Zealand Criminal Courts: a Review of Practice and Policy. ${ }^{73}$ These recommendations are also included in the Issues Paper from the Ministry of Justice: Alternative Pre-trial and Trial Processes for Child Witnesses in New Zealand's Criminal Justice System.

These recommendations are:

(1) that there should be "a presumption in favour of video recorded forensic interviews and CCTV or live audiovisual links for all child witnesses"; ${ }^{74}$ and

(2) that the Evidence Act be amended "to include pre-recording of a child witness's entire evidence, including re-examination and cross-examination."75

These two recommendations are discussed in the Ministry of Justice's Issues Paper, and alternative options are also proposed. Those alternatives will be outlined as part of our consideration of the two recommendations in the following sections. In our discussion, however, we consider the

71 Deutsche Finance New Zealand Limited v Commissioner of Inland Revenue, above $\mathrm{n} 39$ at [11]; $R$ v Ipo HC Auckland CRI-2008-092-1835, 8 October 2009 at [19]; $R v S J P$, above $\mathrm{n} 70$ at [28].

$72 R v M(C A$ 590/2009), above $\mathrm{n}$ 27, at [39]; $R \vee S$ (CA 757/2010) [2011] NZCA 128 at [18]; $R v E(C A$ 308/06) [2008] NZCA 404, [2008] 3 NZLR 145, (2007) 23 CRNZ 976 at [17] in which the Court of Appeal observed:

Given the complainant's age it is standard practice for evidence to be given by the playing of an evidential videotape ... It will require special reason for a videotape not to be used as the evidence in chief of such a young girl.

73 Hanna and others, above $\mathrm{n} 3$.

74 Ibid, at 176.

75 Ibid. 
recommendations in the specific context of sexual cases, but with potential application to the evidence of all complainants, not just children.

\section{A Creation of Presumptions in Favour of Alternative Ways for Vulnerable Witnesses}

The proposal to introduce a presumption in favour of alternative ways of giving evidence (for child witnesses) seems to have been based in part on the following view expressed in Hanna's research: ${ }^{76}$

\footnotetext{
As evidenced over time, law and policy-making do not guarantee effective and consistent implementation on the ground. This is borne out in the current study. The criminal justice system is still finding it difficult to accommodate child witnesses to the extent possible under the current legislative and procedural frameworks ... For example ... [f]ourteen percent of the child witnesses in the 20082009 sample testified without using any alternative modes of evidence.
}

Stated like this, it does seem of concern that, in particular, child complainants are not giving evidence in an alternative way. However, two points need to be made about this statement. First, the study concerned child witnesses, not just complainants - and it is only child complainants for whom the prosecution must seek directions. It may be that the witnesses in these cases were not giving evidence of a particular type or in a level of detail that made seeking a direction appropriate. Secondly, and more significantly, 14 per cent is the equivalent of 10 out of the 71 in the research sample. However, eight of these 10 had expressed a preference to give evidence in the ordinary way and were all over the age of $13 .{ }^{77}$ Given that research has consistently demonstrated the value of children's views being taken into account regarding such decisions, ${ }^{78}$ and the fact that the judge must "have regard" to their views (s 103(4)(b) and s 107(4)(b)) it should be seen as a positive outcome that the children were listened to. This leaves two out of 71 (less than three per cent) who gave evidence in the ordinary way, but for reasons that are not explained or were not apparent to the researchers.

The other relevant piece of research reported in Child Witnesses in the New Zealand Criminal Courts: a Review of Practice and Policy included the statistic that of 131 applications made for a child witness to give evidence in an alternative way, ${ }^{79} 31$ (or 24 per cent) were contested by the defence. Of these 31 contested applications only three applications were disallowed (or two per cent). However, it is not clear if another alternative way was substituted for that applied for - that is,

76 Ibid, at 169 [emphasis added].

77 Ibid, at 38-39.

78 Law Commission Children and Other Vulnerable Witnesses, above n 1, at [C46].

79 Where it was known whether or not the application was contested (out of the total sample of 134): see Hanna and others, above n 3, at 102. 
it is not clear from the discussion of the research if the three unsuccessful applications meant that the witness had to give all their evidence in the ordinary way.

Therefore, based on the research undertaken by the Auckland University of Technology it is not clear that a strong case has been made for introducing a presumption or any other legislative change that would result in the increased use of alternative ways of giving evidence for child witnesses.

Further, there are practical difficulties of creating a presumption in favour of alternative ways of giving evidence when one of the matters to be taken into account is the views of the witness - who may well, as the previous discussion demonstrates, wish to give evidence in the ordinary way. That is, it would be the prosecution who would be required to rebut the presumption on the basis that their child witness (or complainant) did not wish to give evidence in an alternative way.

The matter is further complicated when more than one presumption needs to be rebutted - that is, a presumption in favour of pre-trial pre-recorded cross-examination as well as a presumptive use of alternative ways of giving evidence in the case of any supplementary questioning at the trial itself.

Finally, it is unclear what the positive effect of a presumption will be, as opposed to, for example, the requirement that the prosecution seek directions in every case involving a child witness. In both scenarios the defence will contest the application if they are so instructed, or they will consent to the order being made. The argument has been made that a presumption will reduce time spent on the application process ${ }^{80}$ - but in the case of a presumption the court and the defence would still need to be advised as to which form of alternative way was being requested.

These arguments aside, ${ }^{81}$ we certainly support the use of alternative ways of giving evidence in appropriate cases and, subject to the discussion concerning the recent psychological research, an increased use of alternative ways of giving evidence in cases involving child witnesses and complainants in sexual cases. However, there is currently no New Zealand research to indicate that child witnesses, more particularly child complainants, are being inappropriately denied the ability to give evidence in an alternative way. We also consider that requiring applications to be made regarding how all child witnesses are to give evidence would be an unnecessary change in the absence of further research.

However, given there is research that suggests adult vulnerable witnesses (especially complainants in cases of sexual offending or family violence), ${ }^{82}$ are not always made aware of the potential for them to give evidence in an alternative way we suggest that thought is given to

80 Ibid, at 170 .

81 See other arguments made for and against the introduction of a presumption in favour of an alternative way in Ministry of Justice Issues Paper, above n 12, at [54].

82 Kingi and others, above n 54. 
amending the Evidence Act to require the prosecution to seek directions as to how any complainant in a sexual case should give their evidence. This could include a direction that their evidence is prerecorded, an issue which we now discuss.

\section{B Pre-trial Recording of Evidence: Benefits and Evidential Challenges}

Although s 105 of the Evidence Act invites a focus on determining which alternative way of giving evidence will allow the witness to give his or her "best evidence" (and therefore does not prioritise the ways in which evidence may be given), the Law Commission has recognised that early recording of relevant evidence enhances its reliability, regardless of the age of the witness or the circumstances of the case. ${ }^{83}$ International research regarding the giving of evidence by video record often focuses on children's evidence, and there has been a corresponding concentration in New Zealand. ${ }^{84}$ This article expands the discussion to vulnerable adult witnesses, who may also benefit from the ability to record their evidence in advance of the trial.

Pre-recording of evidence allows for capture of evidence at an earlier stage than trial. How substantial this benefit is may depend on the method of pre-recording employed for each stage of the evidence. The main methods are:

(1) Utilisation of investigative interviews as evidence in chief, with live cross-examination and re-examination.

(2) Pre-recording evidence at a special hearing. This allows for pre-recording of crossexamination and re-examination as well as evidence in chief, but is unlikely to allow for evidence in chief to be heard as close in time to the offence as where the investigative interview is utilised as evidence.

(3) Investigative interviews could be entered as evidence in chief at a special hearing where cross-examination and re-examination are conducted. Supplementary questions in evidence in chief may be asked if necessary. ${ }^{85}$

83 Law Commission The Evidence of Children and Other Vulnerable Witnesses: A Discussion Paper (NZLC PP26, 1996) at [A1] and [A12]. There is some disquiet about the use of early interview material as evidence in chief for those victims who are unable to recall details in a coherent way due to the trauma of the event in the immediate days and weeks following. This is an issue often raised when examining the symptoms of "rape trauma syndrome": see, for example Louise Ellison "Promoting effective case-building in rape cases: a comparative perspective" [2007] Crim LR 691.

84 See Hanna and others, above n 3; Ministry of Justice Issues Paper, above n 12.

85 This was essentially the recommendation of the Pigot Report in England and Wales: Thomas Pigot The report of the advisory group on video evidence (Home Office, 1989); Debbie Cooper "Pigot Unfulfilled: Video-recorded Cross-examination under section 28 of the Youth Justice and Criminal Evidence Act 1999" [2005] Crim LR 456. 
Where a special hearing is held, it could be video-recorded and played at trial for the benefit of the jury. ${ }^{86}$ It should be borne in mind that, should only the evidence in chief be pre-recorded, then any significant delay between evidence in chief and cross-examination may result in greater inconsistencies and therefore (potentially unwarranted) undermining of the credibility of the witness in the eyes of the fact-finder. ${ }^{87}$

\section{Potential benefits of pre-recording evidence: evidence in chief}

A primary benefit of pre-recording evidence is that it preserves information that might be forgotten, and as the evidence is recorded (in the witness's own words if a cognitive interview/narrative form technique is used), the effects of any contamination or distortion of memory over time is reduced. ${ }^{88}$ Where investigative interviews are used as evidence in chief, there is added potential to obtain evidence that offers improved outcomes in memory retrieval and therefore reliability of the evidence. Provided that appropriate interviewing methods are used, then the accuracy of the evidence is likely to be enhanced, particularly as in many cases the interview will have been conducted closer to the time of the offending, before the memory of the witness fades.

As pre-recording allows for full information of the witness's complete evidence at an early stage, its use may improve the decision-making of both prosecution and defence counsel. In this way it has the potential to improve charging decisions and increase early resolution of cases.

Pre-recording also allows for easier use of a "narrative form" of evidence than the giving of evidence at trial. For example, unlike at trial, the evidence can be edited in order to comply with evidential rules. "Narrative form" differs from the normal process of the witness's evidence comprising answers given to questions posed one by one. Rather, evidence given in narrative form allows witnesses to tell "their story" in a format that is accessible to the fact-finder ${ }^{89}$ Allowing a

86 This is the process anticipated by the Ministry of Justice CRM/11/05 and HCG/11/05, above n 11.

87 Mandy Burton, Roger Evans and Andrew Sanders "Vulnerable and intimidated witnesses and the adversarial process in England and Wales" (2007) 11 E\&P 1.

88 A Baddeley, MW Eysenck and MC Anderson Memory (Psychology Press, East Sussex, 2009).

89 The New Zealand Law Society and the New Zealand Psychological Society both expressed support for the use of a narrative form of evidence for children in their submissions on the Ministry of Justice Issues Paper, above n 12: New Zealand Law Society "Alternative pre-trial and trial processes for child witnesses in New Zealand's criminal justice system" (2011) Law Society <www.lawsociety.org.nz>; and Fred Seymour, Suzanne Blackwell and Judith McDougall "Alternative re-trial and trial processes for child witnesses in New Zealand's criminal justice system" (2011) The New Zealand Psychological Society <www.psychology.org.nz>. 
person to arrange their story, or say what happened, in the order which makes most sense to them is arguably more likely to be "listener-friendly": ${ }^{90}$

Giving victims of crime the opportunity to tell their story in their own words in a secure and relaxed atmosphere is not only necessary to protect the interests of individual victims, but it also has the potential to act as an indispensible aid to truth-finding. ${ }^{91}$

Like other alternative ways of giving evidence, an important potential benefit of pre-recording evidence is the assistance it provides in offering protection for complainants from secondary victimisation in the courtroom. It does this by reducing or eliminating the need for giving direct oral evidence at trial, and by potentially allowing recovery to begin at an earlier stage. Because prerecorded evidence is given at an early stage, delays in holding the trial are not as damaging to recovery of the complainant (although it is acknowledged that the need for timely resolution remains for both the defendant and the complainant). Therefore, greater use of pre-recording of evidence may increase the number of victims and witnesses who are prepared to give evidence by making the process of recording the evidence less formal; and may reduce the stress of giving evidence, which will help vulnerable and intimidated witnesses give the best evidence they can.

Many of the goals and benefits of pre-recording evidence could be achieved to varying degrees regardless of the pre-recording method used. However, the increased use of an enhanced cognitive interview technique by police offers a route to specialist interviewers and a reduction in the number of occasions the witness is asked to give evidence. The possibility of using a video-recorded investigative interview both as a tool for investigation and as the witness's evidence in chief therefore warrants further examination.

There is a desire within New Zealand Police to gradually move to video recording interviews with "significant witnesses", who are deemed to require special attention due to vulnerability, intimidation or investigative importance. ${ }^{92}$ The obvious advantage in using the interview as evidence in chief is that it captures the evidence at the earliest possible stage. The recording of interviews aims to reduce the contamination of the witness' account in comparison with traditional techniques of statement taking, which requires a more active process of structuring the account on the part of the interviewing officer. The interviews may be delayed in comparison to traditional

90 Jill Hunter "Battling a Good Story: Cross-examining the Failure of the Law of Evidence" in Paul Roberts and Mike Redmayne (eds) Innovations in Evidence and Proof: Integrating Theory, Research and Teaching (Hart Publishing, Oxford, 2009) 261 at 272.

91 Jonathon Doak "Victims' Rights in Criminal Trials: Prospects for participation" (2005) 32 JLS 294 at 316.

92 Mary Schollum Investigative Interviewing: The Recommendations (New Zealand Police, 2006) at 40. The recommendation in the report was for electronic recording of the evidence of all significant witnesses. 
statement taking in some cases, ${ }^{93}$ but a minor delay may be useful in eliciting the best evidence: internationally there is a realisation that recall may be affected by intoxication and trauma in the initial period after an offence. ${ }^{94}$ Such delays are not to be overplayed, as the interviews will still usually take place close in time to reporting. Recording of the investigative interview should therefore "improve the establishment of facts", 95 although its efficacy is reliant on the utilisation of an interview technique that maximises the accuracy and completeness of the witness's report.

Secondary victimisation of complainants is a risk in all investigations, and is heightened where the interviewer holds erroneous beliefs (for example, "rape myths"96 in sexual violence cases), or utilises inappropriate interviewing techniques. To this end, the Police have in place a cognitive interview training ${ }^{97}$ programme of accreditation ${ }^{98}$ and ongoing workplace assessment. The programme has been implemented to accord with international best practice in interviewing, which takes account of psychological research to allow for the best evidence possible being elicited from witnesses. The techniques draw from research about memory processes and contamination through questioning, ${ }^{99}$ working from an initial standpoint that open questions are generally the best type of

93 Jan Jordan "Worlds Apart? Women, Rape and the Police Reporting Process" (2001) 41 Brit J Criminol 679 at 701-702; Elaine Mossman and others Responding to Sexual Violence: A review of literature on good practice (Ministry of Women's Affairs, 2009) at 73.

94 Louise Ellison "Promoting effective case-building in rape cases: a comparative perspective", above n 83, at 693.

95 Mary Schollum Investigative Interviewing: The Recommendations, above n 92, at 41.

96 See Morrison Torrey "When Will We Be Believed? Rape Myths and the Idea of a Fair Trial in Rape Prosecutions" (1991) 24 UC Davis L Rev 1013, for an example of the effects of stereotypical beliefs on complainants in sexual violence cases.

97 The New Zealand Police have utilised investigative interviewing that uses an enhanced cognitive interview technique. The original cognitive interview technique was developed by Fisher and Geiselman: see RP Fisher and RE Geiselman Memory enhancing techniques for investigative interviewing: the cognitive interview (Thomas, Springfield (IL), 1992).

98 Currently, there are four levels of competency in investigative interviewing within the New Zealand Police: Level 1 (Foundation), at which stage officers may interview victims, witnesses and suspects for volume and priority offences; Level 2 (Advanced), where the officer may interview in relation to serious and complex crime; Level 3 (Specialist Adult Witness) where the officer is a specialist in interviewing for major crime; Level 4 (Advisor) where officers co-ordinate and advise on interviewing for major crime. All recruits and current constables should receive Foundational (Level 1) training while all members of the Criminal Investigations Branch should receive Advanced (Level 2) training. This implements Recommendation 11 from Mary Schollum Investigative Interviewing: The Recommendations, above n 92. There is also a "Supervisor" level.

99 The "PEACE" model can apply to both suspect and witness interviewing. PEACE stands for planning and preparation, engage and explain, account, closure and evaluation. The New Zealand Police have adopted a tiered accreditation structure similar to that operated in a number of English police constabularies, for example see Gloucestershire Constabulary "Investigative Interviewing Policy" (2007) <www.gloucestershire.police.uk>. 
questions, allowing for a detailed answer that is less influenced by the questioner and is therefore more accurate. 100

However, resource and implementation issues mean that many interviews with complainants are still not video-recorded. ${ }^{101}$ In part this is due to the necessarily long term development of the uptake of training. As of June 2009, around 90 staff had been trained as Level Three specialists who were able to interview witnesses to major crime. ${ }^{102}$ Current figures show that Level Three specialist interviewers have increased to 112 (84 accredited and 28 trained but not yet accredited). ${ }^{103}$ Because the Level Three specialists need to conduct high numbers of interviews in order to maintain an appropriate skill level, the number of specialist interviewers will inevitably comprise a small proportion of all police staff.

Even where trained officers are available and the technique used is impeccable, there are evidential challenges in using the pre-recorded interview as evidence in chief. There is a clear difference between the investigative needs of an interview (rapport building, exploratory questioning and the like), and the needs of the courts in the presentation of evidence (which requires evidence that is easily followed and placed into the "frame" of other evidence without being too lengthy). So, whilst video recorded interviews clearly offer advantages in early recording of evidence over other alternative ways of giving evidence, the practical challenges need to be realistically canvassed.

\section{Pre-recording: cross-examination and re-examination}

If more pre-recording of the evidence in chief of adult witnesses takes place, there follows an obvious question of whether the rest of a witness's evidence should also be pre-recorded. The benefits outlined above are not restricted to evidence in chief. For example, more benefits in protection of witnesses from secondary victimisation and reduction of delays in recovery are evident where the whole of a witness's evidence is pre-recorded.

In the context of the general findings on the impact of cross-examination on witness accuracy, concerns have been raised that pre-recording evidence in chief alone may be detrimental to witnesses in some instances. If the video record is to be followed by cross-examination that is not pre-recorded, then many of the more difficult issues for vulnerable witnesses remain. Indeed, the issues may be heightened because the witness will not have had prosecution counsel lead them through the questions in evidence in chief, and their first real exposure to the lawyers in the case

100 BR Clifford and R George "A field evaluation of training in three methods of witness/victim investigative interviewing" (1996) 2 Psychology Crime and Law 231.

101 Elaine Mossman and others, above n 51, at 75.

102 New Zealand Police Annual Report 2008/09 (Wellington, 2009) at 2.

103 Personal communication with NZ Police, May 2011. 
will be during cross-examination. ${ }^{104}$ For this reason, it has been suggested that where a video recorded interview is used as evidence in chief, the prosecutor should ask the witness a few short questions before cross-examination begins (for example: "Do you need a break?" or "Can you see everyone clearly?"). ${ }^{105}$

Research has consistently shown that cross-examination techniques can mislead and confuse witnesses, which in turn impacts on the accuracy of the evidence they give. ${ }^{106} \mathrm{~A}$ recent study replicated previous findings that the use of complex vocabulary and syntax during crossexamination is associated with reduced witness accuracy, but also concluded that prepared witnesses are more likely to seek clarification and give accurate responses. ${ }^{107}$ The method of preparation - a leaflet outlining the purpose of cross-examination, general advice (such as "listen carefully to the question") and examples of leading, multipart and double negative questions - was relatively simple.

According to indications from international research, judges are cautious about interfering in the questioning of witnesses, especially with regard to defence counsel in criminal proceedings. ${ }^{108}$ This may be a result of the best intentions: to avoid an appeal leading to a re-trial as a result of the judge 'descending into the arena' or prejudicing the defence case or trial strategy. Further, the judge in an adversarial model is comparatively ill equipped to effectively intervene in cross-examination as he or she must exercise his or her discretion "within tight structural constraints which militate against the adequate protection of vulnerable witnesses from irrelevant and inappropriate questioning. "109 This is the result of the judge acting as umpire in party-controlled evidence presentation.

104 Louise Ellison The Adversarial Process and the Vulnerable Witness (Oxford University Press, Oxford 2001) at 57; R Flin and others "Child witnesses in Scottish Criminal Trials" (1993) 2 IRV 325.

105 Office for Criminal Justice Reform (UK) Convicting Rapists and Protecting Victims - Justice for Victims of Rape: A Consultation Paper (2006) at 33.

106 See for example J Wheatcroft and G Wagstaff "Cross-examination: The Interface Between Psychology and the Courtroom " (2003) 75 Forensic Update 8; and M Kebbell and S Johnson "Lawyers' Questioning: The Effect of Confusing Questions on Witness Confidence and Accuracy " (2000) 24 Law \& Hum Behav 629. Although much of the work in this area concentrates on the evidence of children, the accuracy and completeness of evidence given by adult witnesses is also affected by cross-examination techniques such as complex questions, leading questions, double negatives and legal terminology.

107 Louise Ellison and Jacqueline Wheatcroft Exploring the Influence of Courtroom Questioning and Pre-Trial Preparation on Adult Witness Accuracy (University of Leeds: Arts \& Humanities Research Council, 2010).

108 Louise Ellison "Rape and the Adversarial Culture of the Courtroom" in Louise Ellison and Mary Childs (eds) Feminist Perspectives on Evidence (Cavendish Publishing, London, 2000) 39 at 48; Jennifer Temkin Rape and the Legal Process (2nd ed, Oxford University Press, New York, 2002) at 9; Reid Howie Associates Vulnerable and Intimidated Witnesses: Review of Provisions in Other Jurisdictions (Scottish Executive Central Research Unit, 2002) at 66; Anne Cossins "Is There a Case for the Legal Representation of Children in Sexual Assault Trials?" (2004) 16 CICJ 160 at 162.

109 Louise Ellison, above n 104, at 110. 
Several jurisdictions, many of them civil law jurisdictions, allow all evidence to be pre-recorded for some witnesses. Western Australia offers an example of a common law jurisdiction that has adopted the approach for child witnesses. It should be noted that the provision in Western Australia relates to video record at a special hearing, as opposed to the investigative interview being recorded and used as evidence in chief. ${ }^{110}$ In 1992, changes were made in Western Australia to the way that children give evidence in some cases, and the substantive criminal law and procedure more generally. A number of the 1992 reforms were aimed at removing the physical and emotional barriers children face when giving evidence. These are inherent in the nature of the adversarial process and the physical court.

The essence of the reforms was to allow children's evidence to be recorded in full (including cross-examination and re-examination) at a special pre-recording hearing so that they would not have to appear at trial. ${ }^{111}$ Editing of the video is governed by s106M of the Evidence Act 1906 (WA), which states that alterations may not occur without the approval of judge. However, in practice, editing is undertaken by the prosecution with defence consultation. ${ }^{112}$ The tape is stored by the court for use at the trial, and rather than being tendered as an exhibit, is treated as oral evidence. ${ }^{113}$ Western Australia has been lauded as a great example of protection of vulnerable witnesses. However, as the pre-recording often takes place fairly close to the time of the trial (there is often no pre-recording at all if there will not be a delay in hearing the case), some of its benefits -

110 A number of other Australian jurisdictions provide for pre-recording of evidence: for example, the Northern Territory of Australia also has provision for the use of the pre-recorded interview to be used as evidence in chief and for recording of the evidence at a special sitting: Evidence Act 1939 (NT), ss 21A(1), s 21B and s 21C; and South Australia, where an audio-visual record may comprise all or part of a vulnerable witness's evidence, including cross- and re-examination: Evidence Act 1929 (SA), ss 13A and 13C.

111 Pre-recording of a child's evidence is governed by ss $106 \mathrm{I}$ to $106 \mathrm{MB}$ of the Evidence Act 1906 (WA):

106I. Visual recording of child's evidence, application for directions

(1) Where a Schedule 7 proceeding has been commenced in a court, the prosecutor may apply to a judge of that court for an order directing -

[(a) deleted]

(b) that the whole of the affected child's evidence (including cross-examination and reexamination) be -

(i) taken at a special hearing and recorded on a visual recording; and

(ii) presented to the court in the form of that visual recording,

and that the affected child not be present at the proceeding.

112 Hanna and others, above n 3 , at 151 .

113 Hal Jackson "Child Witnesses in the Western Australia Criminal Courts" (2003) 27 Crim LJ 199 at 210. 
avoiding forgetting by recording the interview close to the time of the offence, for example - are irrelevant.

The Scottish process for taking the evidence of child witnesses "on commission" in s 271I Criminal Procedure (Scotland) Act 1995 has similarities with the Western Australian approach. Under the Scottish legislation, a High Court judge or sheriff is appointed as Commissioner to take the child's evidence. There is also provision for the child's statement (including police interviews) to constitute evidence in chief (s 271M). In England and Wales, s 28 of the Youth Justice and Criminal Evidence Act 1999 (UK) provides for cross-examination and re-examination to be pre-recorded. However, the section has proven to be controversial, has not yet been adequately piloted and at one stage looked to be headed for repeal before it came into force. ${ }^{114}$ The British government has not repealed the section in the new legislation, but it has still not been implemented (it is "partially" in force).

In many ways the issue of pre-recording is less evidentially complex in civil law jurisdictions: most civil law jurisdictions have few evidential rules, and there is little formal distinction between evidence in chief and cross-examination as the judge will usually lead the questioning. ${ }^{115}$ For example, as we indicated in Part II of this article, the "contradictory interrogation" procedure in Austria, used primarily in sexual offence cases, provides that the complete evidence of the witness is received and videotaped in advance of the trial and may then be used at the trial in lieu of oral evidence. While the evidence is being taken, the witness and the judge or specialist interviewer are in one room and other participants are in a second room that is joined by audiovisual link. The victim provides his or her evidence as a narrative, followed by questions from the judge or interviewer. The judge then goes to the other room and collects questions from the other parties to put to the witness. There is no ability of the parties to put questions directly to the witness.

In Part II we outlined the possibility that a pre-recording could be used at any re-trial. Some jurisdictions ${ }^{116}$ allow for either pre-trial recording of evidence, or for the recording of the evidence given at trial, in both cases to avoid the witness having to give evidence in person at any re-trial. However, new issues may be introduced between the original trial and the re-trial; and the witness

114 Diane Birch and Rhonda Powell Meeting the Challenges of Pigot: Pre-trial Cross-examination under s 28 of the Youth Justice and Criminal Evidence Act 1999 (2004) in Office for Criminal Justice Reform (UK) Improving the Criminal Trial Process for Young Witnesses (2007) at 12.

115 In the Netherlands, rape complainants can usually give evidence at a pre-trial hearing held before an examining magistrate. The examining magistrate controls the questioning, although the defendant's lawyer is able to ask questions. This does not necessarily protect the complainant from secondary victimisation. As Ellison reports, defence lawyers may still utilise stereotypes of appropriate behaviour and victim blaming; and irrelevant and offensive questions may still occur: Louise Ellison "The protection of vulnerable witnesses in court: An Anglo-Dutch comparison" (1999) 3 E\&P 29.

116 For example the Northern Territory of Australia (Evidence Act 1939 (NT), s 21E) and South Australia (Evidence Act 1929 (SA), s 13D). 
may thereby feel obliged to give evidence some other way after all - this problem can arise with any system of pre-recording (for example, new evidence in a first trial may arise between the prerecording and the trial). It can also be an issue in civil law jurisdictions, with witnesses facing the choice of sticking to the pre-recorded evidence and not having their response to the new evidence heard; or having to give evidence that is not pre-recorded. Legislative provision for giving supplementary evidence in an alternative way, including pre-recording, can assist in reducing the effect of this problem.

\section{Evidential challenges relating to pre-recording of evidence}

In assessing the evidential challenges involved in pre-recording of evidence, England and Wales serves as a useful case study of pre-recording generally, and use of the investigative interview as evidence in chief in particular. The "Stern Review" reported in March 2010, and reflected some of the concern in the English legal profession about the increasing use of video-recorded interviews being used as evidence in chief. The review reported that there was anecdotal evidence of disquiet at the volume of video-recorded evidence, the length of the evidence and a feeling that "juries prefer theatre to film". ${ }^{117}$

It is worth reproducing an excerpt from Baroness Stern's conclusions here: ${ }^{118}$

One person we spoke to told us, "The ABE [Achieving Best Evidence] interview introduced structure to interviews, but it has become so rigid it is almost counter-productive".

.

These video-recorded interviews can be interminably long because investigating police officers have, it is said, been advised to let victims say as much as possible at their own pace. We heard from a judge that in one particular case, "the ABE interview DVD was 5 hours and 38 minutes long. This is an affront to the notion of best evidence. The police must respect the best interests of the complainant by keeping the statement/DVD of evidence as short as necessarily practicable."

117 Vivian Stern The Stern Review, above n 61, at 16. The contention that "juries prefer theatre to film" is discussed below in Part IV C.

118 Ibid, at 68-69. It should be noted that the concerns in The Stern Review were anecdotal, and do not reflect a Home Office review of special measures three years earlier, which found that "achieving best evidence" interviews (video-recorded investigative interviews) were conducted in only a minority of cases (33 per cent of adult vulnerable and intimidated witnesses and 25 per cent of child cases despite a presumption for such interviews for children). See Mandy Burton, Roger Evans and Andrew Sanders Are special measures for vulnerable and intimidated witnesses working? Evidence from the criminal justice agencies (Home Office Online Report 10/06, 2006). This was despite 75 per cent of police in the research survey rating video evidence as the most effective special measure of all. 
We were also told, "In the case of adult witnesses, it is surely essential for a written statement to be made based upon the relevant issues dealt with in the video interview." We heard of one area where there is a local rule that all video interviews are to be edited down to no more than 45 minutes unless there are good reasons for a longer interview.

The concerns in England and Wales highlight a number of issues which may impact on the admissibility of the evidence and the ability of the jury to properly assess it. These are reflected in the Evidence Act in New Zealand, where rules of evidence may sit uncomfortably with the use of an investigative interview as evidence in chief in particular - from requirements of relevance, through to the rules governing hearsay and previous consistent statements.

In order for video recorded investigative interviews to be appropriately utilised as evidence in chief, it is necessary to assess whether the investigative needs of the interview can be achieved whilst also fulfilling the requirements of a sound evidential product. The police interview is - and has to be - focussed on investigative needs. The task is to gauge whether the same interview can adequately fulfil the evidential needs of the courts. If this can be achieved, then the potential for video recorded interviews as evidence in chief is significant. Whilst the challenges presented by prerecording are discussed here in relation to the investigative interview, a number of the issues discussed below are pertinent to all pre-recording.

First, the length of the pre-recorded evidence using a narrative form of evidence may be prohibitive, because in allowing the witness to tell their own story the evidence will not focus on what counsel think is relevant to the issues, but on what is important to the witness in recalling events and presenting the story as he or she experienced it. This challenge may be magnified where the pre-recording consists of an investigative interview because police will rightly wish to gain as full an account as possible. Specifically, the pre-recording may not satisfy the requirement that all evidence is relevant, ${ }^{119}$ or in extreme cases may offend s 8 of the Evidence Act in needlessly prolonging the proceedings. Any effort made to keep the pre-recording or interview as concise as possible may undermine some of the benefits of a narrative form or cognitive interview approach. In relation to utilising the investigative interview as evidence in chief, this reflects the tension in obtaining both a good investigative and good evidential product.

Secondly, an account in the witness's own words will not usually be in chronological order and may not be well structured or in any logical order at all. This effect may be magnified where a victim is still traumatised by the offence. Therefore, a video record of evidence in chief may not be particularly accessible for use by counsel in preparation for trial or cross-examination. In addition, vulnerable witnesses may be wary if a copy of the video-record is supplied to defence counsel,

119 See s 7 of the Evidence Act (relevant evidence has a "tendency to prove or disprove anything that is of consequence in determining the proceeding"). 
fearing inadvertent loss or misuse of the evidence. ${ }^{120} \mathrm{~A}$ transcript of the recording may be provided to counsel in lieu of the recording in order to address this, which would be produced automatically where evidence is recorded at a special hearing, ${ }^{121}$ but would be time-consuming for investigative interviews. Where the investigative interview is used as evidence in chief, a written statement could be produced in the traditional way (based on the issues in the video record). Written statements will continue to play an important part in the criminal process even if there is greater video-recording of the investigative interview, but it must be noted that such statements may result in contamination and incompleteness of evidence because police officers will inevitably have an effect on the content of the statement they produce for the witness to sign. ${ }^{122}$ Any written statement is therefore unlikely to be as accurate or complete as a video record, meaning that care must be in taken in the way they are used in conjunction with video-recorded evidence.

Thirdly, the ability of counsel to emphasise particular parts of the witness's evidence in order to present it more persuasively is also obviously reduced when using any narrative or open-ended form of evidence. It is particularly so when the pre-recorded interview is used as evidence in chief, because the police have interviewed the witness for investigative purposes in order to obtain as full an account as possible. Prosecuting counsel is not able to structure the narrative of the witness's evidence, because the themes and content of the witness's "story" are already in the video interview. This returns the focus to whether, given the circumstances of the witness and the considerations in subss 103(3) and 103(4), the use of a pre-recorded interview as evidence in chief is the best way of "maximising the quality" of the evidence.

Fourthly, the editing of video records may be a useful method of ensuring that the evidence is relevant and as short as possible, but comes with its own challenges, in that the editor needs to be skilled in order to avoid inadvertently removing parts of the evidence that are important to the assessment of credibility or of other evidence. The use of a chronological summary may assist with appropriate editing to ensure compliance with the rules of evidence, whilst ensuring that an accurate representation of the witness's evidence is not lost. Although New Zealand has experience in editing

120 This is not to suggest that defence counsel would act unprofessionally; rather to acknowledge the sensitivity inevitably felt by a witness who has been video-recorded giving evidence, particularly where the evidence concerns intimate issues. The protocol released by the Ministry of Justice provides that Crown and defence counsel will not automatically be entitled to access any of the DVDs containing evidence recorded at a special hearing, but copies may be provided in exceptional circumstances (on application to a Judge): Ministry of Justice CRM/11/05 and HCG/11/05, above n 11.

121 Where evidence is recorded at a special hearing, there will be contemporaneous transcription with copies distributed to participants: Ministry of Justice CRM/11/05 and HCG/11/05, above n 11.

122 This is an acknowledged problem with the traditional method of statement-taking: ME Lamb and others "Accuracy of investigators' verbatim notes of their forensic interviews with alleged child abuse victims" (2000) 24 Law \& Hum Behav 699. 
children's video interview evidence, children tend to give shorter and less detailed responses, ${ }^{123}$ meaning that the task is not as complex as it would be for most adults.

Finally, where new evidence or issues arise, the courts will need to carefully navigate decisions on applications for giving supplementary evidence in order to ensure that the temporal benefits of pre-recording are not undermined. In particular, any provision for supplementary cross-examination would need to take care in relation to protection of vulnerable witnesses. There have also been objections to pre-recording of cross-examination because it forces the defence to disclose particulars of their case before trial. ${ }^{124}$ How pertinent an objection this would be in the New Zealand context may depend on the eventual form of defence identification of issues. ${ }^{125}$

It is submitted that these challenges are not insurmountable, but do require us to have a legal cultural shift in relation to traditional views of the trial and the giving of evidence. The benefits are persuasive: victims would not have to relive the offence in the retelling so often; evidence could be collected close in time to the offending (in acute presentations to police); and victims would be able to say what happened in a free narrative/enhanced cognitive interview form.

However, more accurate retrieval of memory could also be achieved by more effective fast tracking of cases involving vulnerable witnesses. If all the main witness's evidence is pre-recorded, the parties need to be prepared in time for the pre-recording hearing and it may make more sense to hear the trial at an earlier date instead. A risk of pre-recording is that the cases will then be deprioritised, and neither defendant nor witness will be able to achieve resolution in a timely manner.

In addition, the undoubted benefits in recall (and therefore reliability) need to be weighed against the difficulties in each individual case of presenting relevant evidence in a digestible format for the jury, ${ }^{126}$ but it is also useful to consider the available research regarding the general effect of

123 N Westera, M Kebbell and R Milne "Interviewing witnesses: Do investigative and evidential requirements concur?" (2011) 13 British Journal of Forensic Practice 103 at 107.

124 LCH Hoyano and C Keenan Child abuse: Law and Policy Across Boundaries (Oxford University Press, Oxford, 2007) at 642 .

125 At the time of writing, the Criminal Procedure (Reform and Modernisation) Bill 243-1 (2010), cl 64 provided that before trial the defendant must give notice of particular elements of the offence that the defence contended could not be proved, and notice of any particular defence on which the defendant intended to rely. This was amended after the Select Committee process to remove the word "particular" in order to make it clear that the defence were not required to disclose its factual case to the prosecution before trial (243-2 (2010), cl 64). As this article went to press, cl 64 was deleted and an amendment was made to cl 54 , so that an indication of any fact or issue the defence intends to dispute or rely on at trial can be included in case memorandums only if the defendant wishes: Criminal Procedure Bill 243-3A (2010)). This was passed on 4 October 2011 as the Criminal Procedure Act 2011.

126 A popular conception of how juries form a view of the case is the "story model", which suggests that jurors do not simply record and store the evidence for later use as they receive it. Instead, they organise the evidence to construct a story, which can then be used to fill in gaps in the evidence by drawing inferences. There is little research on how pre-recorded video interviews used as evidence in chief might fit in with this 
alternative ways of giving evidence on the fact-finder's assessment of credibility and decisionmaking.

\section{The Psychological Research Regarding Use of Alternative Ways of Giving Evidence}

In discussing potential reform or enhancement of the current provisions for giving evidence in an alternative way, it is necessary to assess whether it is possible to address the concerns of complainants without unfairly impacting on a defendant's right to a fair trial. There is not scope in this article to attempt a full Bill of Rights Act 1990 analysis of this issue. ${ }^{127}$ Instead, the discussion below focuses on the most frequent arguments with regard to s 103(4), which revolve around the impact of alternative ways of giving evidence on the perception of the accused by the jury, and the difficulty of assessing the demeanour of witnesses who give evidence via CCTV or on pre-recorded video tape. Section 123 of the Evidence Act attempts to prevent any adverse inference being drawn against the defendant where a witness has offered evidence in an alternative way. By virtue of s 123, the judge is required to direct the jury that the law makes special provision for the manner in which evidence is to be given and that it must not draw any adverse inference against the defendant because of the manner in which evidence is given. There is no direction as to the timing of the direction, which may be given immediately before the witness gives evidence, as part of the summing-up, or both. ${ }^{128}$

The ability to adequately assess credibility of witnesses who give evidence in an alternative way has occasionally been questioned since the 2006 Evidence Act was introduced. As we state in Part III, arguments that evidence given by CCTV or pre-recorded videotape affects the jury's ability to

type of process. For an early description of the story model, see N Pennington and R Hastie "Evidence evaluation in complex decision making" (1986) 51 J Pers Soc Psychol 252.

127 The right to confrontation is arguably affected by a regime of pre-recording, particularly where crossexamination is pre-recorded (see New Zealand Bill of Rights Act 1990, s 25(f)). The New Zealand Law Commission, in discussing appropriate means of giving evidence for vulnerable witnesses, argued that the right does not include face to face confrontation: see Law Commission The Evidence of Children and Other Vulnerable Witnesses, above $\mathrm{n}$ 1, for a discussion of the Bill of Rights fair trial issues with regard to vulnerable witnesses. There is currently little evidence to suggest that face-to-face confrontation is required in order to assess credibility, although it is acknowledged that pre-recording of cross-examination requires counsel to address cross-examination issues prior to the trial. In other ways, pre-recording without intermediaries allows "confrontation" by way of direct questions from counsel in the normal way, albeit presented to the jury at a later date.

128 There is some evidence that directions given later in the case (such as in the summing up) have little effect on decision-making: JD Lieberman and J Arndt "Understanding the limits of limiting instruction: Social psychological explanations for the failure of instructions to disregard, pre-trial publicity and other inadmissible evidence" (2000) 6 Psych Pub Pol'y \& L 677. There may possibly be a danger in emphasising the evidence should a direction be given at more than one point in the trial. 
assess demeanour and veracity have not generally been accepted. ${ }^{129}$ All in all, the courts have not generally accepted arguments that suggest that alternative ways of giving evidence preclude a fair trial. ${ }^{130}$ This section assesses whether the Court of Appeal was correct in agreeing with Crown counsel's observation that "evidence by video link has not previously been seen as adversely affecting an ability to assess credibility." 131

Before discussing the possible effect of alternative ways of giving evidence in particular, it is important to put in context concerns regarding the effect of different modes of evidence on the ability of the fact-finder to assess credibility. It is well accepted that human beings are very poor at assessing credibility: we may think that we can gain skill in credibility assessment (as popularised by television programmes such as "Lie to Me"), but in fact all people are remarkably unsuccessful in discriminating between truthful and untruthful witnesses. Psychological research outlines just how poor the average person is at assessing truthfulness: for example, a meta-analysis of 206 studies concluded that "the average person discriminates lies from truths at a level slightly better than he or she could achieve by flipping a coin". ${ }^{132}$ Professionals and lay persons have broadly the same ability to detect truth from lies, sharing the same misconceptions about how people behave when they are lying. ${ }^{133}$ There is similarly little evidence to suggest that non-verbal cues (such as emotional response) offer any reliable basis for detecting lies. ${ }^{134}$

We argue then, that the real issue with regard to the effect of alternative ways on credibility assessments by the fact-finder is not whether any particular alternative way actually affects the ability of the fact-finder to assess credibility; but rather whether the mode of evidence might illegitimately affect the perceptions of credibility held by the fact-finder. Indeed, the limited studies which assess whether mode of evidence affects the ability of jurors to assess credibility suggest that there is no difference in detection of truth or lies between face to face and out-of-court modes. ${ }^{135}$

129 See Part III and above, n 39.

130 In Mussa $v$ R [2010] NZCA 123 the Court of Appeal stated at [48]:

We do not accept that allowing [an adult] complainant in a rape case to give evidence from behind a screen deprives the accused person of the right to a fair trial. The assertion that the jury would consider the complainant needed protection from the appellant assumes they ignored the Judge's clear direction that they should not do so. There is nothing to indicate that that is what happened.

$131 R v$ Simi [2008] NZCA 515 at [27]. See part III, and above n 41.

132 CF Bond Jr and BM DePaulo "Accuracy of Deception Judgments" (2006) 10 PSPR 214 at 230.

133 Aldert Vrij, Par Anders Granhag and Stephen Porter "Pitfalls and Opportunities in Nonverbal and Verbal Lie Detection" [2010] PSPI 1.

134 SL Sporer and B Schwandt," Moderators of non-verbal indicators of deception: A meta-analytic synthesis" (2007) 13 Psych Pub Pol'y \& L 1.

135 See, for example, HK Orcutt and others, above n 42. This study compared face-to-face evidence with evidence given via CCTV. 
This suggests in turn that the approach in s 5 of the Courts (Remote Participation) Act 2010 of inquiring into the ability to assess the credibility of witnesses is misguided.

In relation to the effect on fact-finder perceptions of credibility, the research does not offer such a straightforward signal. Studies in the context of eyewitness testimony have shown that the perceived credibility of victims and witnesses are affected by a number of factors relating to appearance and behaviour. ${ }^{136}$ Furthermore, a series of psychological experiments concluded that the perceived credibility of a female rape complainant is influenced by the emotions she displays when giving evidence. In these experiments, an emotive and visibly upset complainant was perceived to be more credible than complainants who appeared calm or relaxed. ${ }^{137}$ This keys into societal expectations and beliefs, so that witnesses who do not show the emotional behaviour expected of them in a given situation may be assessed as lacking credibility. ${ }^{138}$ For example, if a witness is giving evidence in a more comfortable setting than the courtroom (for example via CCTV or at a pre-recording hearing), this may mean that the witness is less nervous and emotional. If the investigative interview is used as evidence in chief, the witness may be more emotional and thereby appear more credible. Neither increased nor decreased emotionality is an indicator of truthfulness (or the lack thereof) but fact-finders may think it is. ${ }^{139}$

In terms of the psychological research on the effect of alternative ways of giving evidence, claims have been made that video technology will increase the likelihood of conviction because jurors will perceive the testimony as in some sense 'special' and that will lead them to pay undue attention to it. ${ }^{140}$ Conversely, others have asserted that video will serve to distance the witness from the jury and cause the witness's evidence to have less emotional impact on the jury compared to live

136 Recent examples include MG Frank and P Ekman "Appearing truthful generalizes across different deception situations" (2004) 86 J Pers Soc Psychol 486 and MR Rose, J Nadler and J Clark "Appropriately upset? Emotion norms and perception of crime victims" (2006) 30 Law \& Hum Behav 203.

137 GC Bollingmo and others "Credibility of the emotional witness: A study of ratings by police investigators" (2008) 14 PC\&L 29; and EM Wessel and others "Credibility of the emotional witness: A study by court judges" (2006) 30 Law \& Hum Behav 221.

138 MR Rose, J Nadler and J Clark "Appropriately upset? Emotion norms and perception of crime victims" (2006) 30 Law \& Hum Behav 203.

139 When reviewing experiments across different offence types and methodologies, there is no clear conclusion on the effect of emotionality on fact-finders' perceptions or decision-making: see Natalie Taylor and Jacqueline Joudo The impact of pre-recorded video and closed circuit television testimony by adult sexual assault complainants on jury decision-making: an experimental study (Research and Public Policy Series No 68, Australian Institute of Criminology, 2005) at 12-19.

140 For a discussion of these claims, see JC Wilson and GM Davies "An Evaluation of the Use of Videotaped Evidence for Juvenile Witnesses in Criminal Courts in England and Wales" (1999) 7 EJCPR 81. 
testimony. ${ }^{141}$ Despite these assertions, there is little psychological research on juror perceptions of pre-recorded evidence of adult witnesses.

One useful example is a report by Taylor and Joudo, ${ }^{142}$ which broke new ground in comparing the impact of face-to-face open courtroom adult sexual assault testimony with CCTV or prerecorded video on juror perceptions of victim credibility, empathy, perceptions of guilt and verdicts. Taylor and Joudo conducted 18 experimental trials in a mock courtroom in the Law School at the University of Canberra. 210 jurors participated in 18 mock juries, with each jury composed of similar numbers of males, females, younger and older persons. The script for the trial was based on a transcript from an actual sexual assault court case, with jurors watching part of a mock trial lasting one and a quarter hours (in which only the complainant gave testimony). After watching the trial but before jury deliberation, jurors completed individual questionnaires regarding their perceptions of complainant credibility, empathy with the complainant, overall impression of the complainant, empathy with the accused, overall impression of the accused and personal beliefs about guilt of the accused. After deliberating for an hour, jurors completed a questionnaire about their beliefs about guilt of the accused. Jurors also completed a questionnaire about their attitudes toward rape victims in general.

Taylor and Joudo found that immediately following the trial, but before jury deliberation, mode of presentation of a complainant's testimony (face-to-face, CCTV or pre-recorded videotape) made little difference to juror perceptions of the complainant, the accused, or the guilt of the accused. There was a diverse spread of juror views regarding credibility, empathy and guilt in all conditions. It is difficult to extrapolate the findings to the possible effects of different modes of evidence on eventual verdicts, as of the 18 juries in the study, 16 were hung. However, indications that jurors subscribed to erroneous beliefs about rape and the way that rape victims behave were very clear. The researchers concluded that: ${ }^{143}$

The findings in this study do not suggest that mode of presentation per se impacts detrimentally in any meaningful or consistent way on jury outcomes for either the complainant or the accused. Rather, the findings suggest that what may be much more important than the manner in which testimony is presented are the pre-existing attitudes, biases and expectations that jurors bring with them into the courtroom.

Most of the research conducted on mode of presentation has concerned children's evidence: much of this indicates that children who give out-of-court evidence are perceived in more negative

$141 \mathrm{~K}$ McFarlane "Diagnositic evaluations and the use of videotapes in child sexual abuse cases" (1985) $40 \mathrm{U}$ Miami L Rev 135.

142 Natalie Taylor and Jacqueline Joudo, above n 139. The authors themselves concede that the use of a 42 -inch plasma screen and good recording conditions may have affected these results.

143 Ibid, at 66. 
terms than children who give in-court evidence, with those giving evidence out of court being perceived as less believable and accurate. ${ }^{144}$ This conclusion accords with the anecdotal evidence described in the Stern Review, with live testimony having a greater emotional impact, and perceived as more credible than CCTV and video evidence in chief. Landstrom recently replicated this basic conclusion in a number of doctoral thesis studies, finding that for both adults and children, live testimony was viewed more favourably than either CCTV or pre-recorded testimony, but that the ability to differentiate between true and false statements were poor whatever the presentation mode. ${ }^{145}$

Despite the tentative finding that fact-finders may have a preference for live evidence, studies indicate that they do not appear to allow it to influence their decision-making, with mode of presentation having little impact on the overall proportion of guilty verdicts in several studies. ${ }^{146}$ It therefore must be concluded that there is no current evidence to suggest that the use of alternative ways of giving evidence affects the actual ability of fact-finders to assess demeanour or credibility. Similarly, there is little scientific evidence to suggest that the perception of the defendant is adversely affected in the ultimate assessment of guilt or innocence. In fact, tentative findings on the emotional impact of evidence given in an alternative way suggest that evidence given "out of court" may have less impact and is perceived as less credible. This in turn suggests that the negative impact and perception is borne by the witness giving evidence in an alternative way, although again this has not been shown to affect the ultimate decision-making of jurors.

It should be stressed that extrapolation to real life from psychological research is not straightforward. Unlike in most experiments, in a real courtroom there is more pressure on factfinders to reach an accurate verdict, no ability to control variables and often an unpredictable unfolding of events. However, until or unless there is verifiable evidence that alternative ways of giving evidence affects the ability of jurors to assess credibility (or indeed affects their ultimate decision-making), then it must be concluded that the approach of the courts so far has been correct.

\section{CONCLUSION}

This article has sought to examine calls for reform to the use of alternative ways of giving evidence within the context of our own research. Fifteen years after the rejection of pre-trial recording of cross-examination by the Law Commission, there is a movement within courts and the

144 Gail S Goodman and others "Face-to-Face Confrontation: Effects of Closed-Circuit Technology on Children's Eyewitness Testimony and Jurors' Decisions" (1998) 22 Law \& Hum Behav 165; HK Orcutt and others, above n 42.

145 Sara Landstrom "CCTV, Live and Videotapes How Presentation Mode Affects the Evaluation of Witnesses" (PhD Thesis, University of Gothenburg, 2008).

146 See for example, Graham Davies "The Impact of Television on the Presentation and Reception of Children's Testimony" (1999) 22 Int'1 J L \& Psychiatry 241. 
policy arena to revisit the issue. Before any larger scale reform is contemplated, there is a need to examine the operation of the law at present, the justifications for change, and the challenges that such change may bring. The current legislation and case law arising from it illustrate that there is a willingness on the part of many prosecutors and judges to expand the use of pre-recording of evidence, but whether this can be accommodated by the specific terms of the Evidence Act is unclear. $^{147}$

In assessing the current reform proposals, it is apparent that there is not yet any compelling evidence to suggest that there is a need for presumption in favour of alternative ways of giving evidence for vulnerable witnesses. However, there is evidence to suggest that adult vulnerable witnesses are not always aware that they may be able to give evidence in an alternative way. We are of the view that there should be consideration given to amending the Evidence Act to require the prosecution to seek directions as to how some vulnerable witnesses should give evidence.

Pre-trial recording of evidence offers significant potential benefits to individual witnesses and the truth finding process. However, there are evidential challenges within our current process, particularly where the investigative interview is used as evidence in chief, or where crossexamination is conducted at a much later date than the evidence in chief. It is submitted that, in appropriate cases, these challenges will not be insurmountable, but that there remains a need to assess the appropriateness of any alternative way of giving evidence in the context of the case and the needs of the witness. The adversarial mode of trial magnifies the difficulties and challenges, and the ease of use of pre-trial recording of evidence may depend on any other reforms contemplated for particular types of offence or witness. Many of the benefits of pre-recording of evidence could be achieved by fast-tracking applicable cases rather than pre-recording evidence.

After assessing the current psychological research on the effect of mode of evidence on factfinders, and examining the practical and evidential challenges of an increased use of pre-trial recording, we conclude that the potential for pre-recording evidence of vulnerable witnesses should be explored further, particularly as an option where fast-tracking of a case is not possible. Whilst it is relatively settled that it is unlikely that the giving of evidence in an alternative way will affect the actual ability of the fact-finder to assess credibility, psychological data on the effect of evidence given in alternative ways on the perception of credibility is relatively sparse, and what data there is cannot easily be extrapolated to the real-life trial. Until more is known about the general effect on juries of alternative ways of giving evidence, experimental results should be approached with caution.

In our view, close consideration of the individual circumstances of the case (utilising s 103) continues to offer the best approach in assessing the needs of a vulnerable witness, the provision of

147 Although it is assumed by the Ministry of Justice that pre-recording of all of a witness's evidence is provided for by the Act: Ministry of Justice CRM/11/05 and HCG/11/05, above n 11. 
a fair trial for defendants, and the most appropriate method of maximising the quality of the evidence. In appropriate cases the possibility of pre-trial recording of all of a witness's evidence warrants consideration alongside other alternative ways of giving evidence. 
